\title{
The experience sampling method as an mHealth tool to support self-monitoring, self-insight, and personalized health care in clinical practice
}

Citation for published version (APA):

ESM-MERGE Investigators (2017). The experience sampling method as an mHealth tool to support selfmonitoring, self-insight, and personalized health care in clinical practice. Depression and Anxiety, 34(6), 481-493. https://doi.org/10.1002/da.22647

Document status and date:

Published: 01/06/2017

DOI:

10.1002/da.22647

Document Version:

Publisher's PDF, also known as Version of record

Document license:

Taverne

Please check the document version of this publication:

- A submitted manuscript is the version of the article upon submission and before peer-review. There can be important differences between the submitted version and the official published version of record.

People interested in the research are advised to contact the author for the final version of the publication, or visit the DOI to the publisher's website.

- The final author version and the galley proof are versions of the publication after peer review.

- The final published version features the final layout of the paper including the volume, issue and page numbers.

Link to publication

\footnotetext{
General rights rights.

- You may freely distribute the URL identifying the publication in the public portal. please follow below link for the End User Agreement:

www.umlib.nl/taverne-license

Take down policy

If you believe that this document breaches copyright please contact us at:

repository@maastrichtuniversity.nl

providing details and we will investigate your claim.
}

Copyright and moral rights for the publications made accessible in the public portal are retained by the authors and/or other copyright owners and it is a condition of accessing publications that users recognise and abide by the legal requirements associated with these

- Users may download and print one copy of any publication from the public portal for the purpose of private study or research.

- You may not further distribute the material or use it for any profit-making activity or commercial gain

If the publication is distributed under the terms of Article 25fa of the Dutch Copyright Act, indicated by the "Taverne" license above, 


\title{
The experience sampling method as an mHealth tool to support self-monitoring, self-insight, and personalized health care in clinical practice
}

\author{
Jim van Os $\mathrm{PhD}^{1,2}$ (D) | Simone Verhagen $\mathrm{MSc}^{1}$ | Anne Marsman $\mathrm{MSc}^{1}$ \\ Frenk Peeters PhD ${ }^{1}$ | Maarten Bak PhD ${ }^{1}$ | Machteld Marcelis PhD ${ }^{1,3}$ \\ Marjan Drukker $\mathrm{PhD}^{1}$ \\ Ulrich Reininghaus $\mathrm{PhD}^{1,4}$ | Nele Jacobs $\mathrm{PhD}^{1,3}$ \\ Tineke Lataster PhD ${ }^{1}$ | Claudia Simons PhD ${ }^{1,5}$ | ESM-MERGE Investigators PhD ${ }^{1 *}$ | \\ Richel Lousberg PhD ${ }^{1}$ | Sinan Gülöksüz PhD $^{1,6}$ | Carsten Leue MSc ${ }^{1}$ | \\ Peter C. Groot PhD ${ }^{1}$ | Wolfgang Viechtbauer PhD ${ }^{1}$ | Philippe Delespaul PhD ${ }^{1}$
}

1Department of Psychiatry, Brain Center Rudolf
Magnus, University Medical Center Utrecht,
Utrecht, The Netherlands
${ }^{2}$ Department of Psychosis Studies, Institute
of Psychiatry, King's Health Partners, King's
College London, London, UK
${ }^{3}$ Faculty of Psychology and Educational
Sciences, Open University of the Netherlands,
Heerlen, The Netherlands
${ }^{4}$ Centre for Epidemiology and Public Health,
Health Service and Population Research
Department, Institute of Psychiatry, Psychol-
ogy \& Neuroscience, King's College London,
London, UK
${ }^{5}$ GGzE, Institute for Mental Health Care
Eindhoven and De Kempen, Eindhoven, The
Netherlands
${ }^{6}$ Department of Psychiatry, Yale School of
Medicine, New Haven, CT, USA
Correspondence
Jim van Os, Department of Psychiatry University
Medical Centre Utrecht, PO BOX85500, 3508
GA Utrecht, The Netherlands.
Email: j.vanos@maastrichtuniversity.nl
*ESM-MERGE investigators are Cécile Henquet,
Mariëlle Lardinois, Mayke Janssens, Nicole
Geschwind, Marieke C. Wichers, Martine van
Nierop, Johan Lataster, Viviane Thewissen.
Grant sponsor: Netherlands Organisation for
Scientific Research; Contract grant number: $451-$
13-022; Grant sponsor: Weijerhorst Stichting;
Grant sponsor: European Community's Seventh
Framework Program; Contract grant number:
HEALTH-F2-2009-241909.

Background: The experience sampling method (ESM) builds an intensive time series of experiences and contexts in the flow of daily life, typically consisting of around 70 reports, collected at 8-10 random time points per day over a period of up to 10 days.

Methods: With the advent of widespread smartphone use, ESM can be used in routine clinical practice. Multiple examples of ESM data collections across different patient groups and settings are shown and discussed, varying from an ESM evaluation of a 6-week randomized trial of mindfulness, to a twin study on emotion dynamics in daily life.

Results: Research shows that ESM-based self-monitoring and feedback can enhance resilience by strengthening the capacity to use natural rewards. Personalized trajectories of starting or stopping medication can be more easily initiated and predicted if sensitive feedback data are available in real time. In addition, personalized trajectories of symptoms, cognitive abilities, symptoms impacting on other symptoms, the capacity of the dynamic system of mental health to "bounce back" from disturbance, and patterns of environmental reactivity yield uniquely personal data to support shared decision making and prediction in clinical practice. Finally, ESM makes it possible to develop insight into previous implicit patterns of thought, experience, and behavior, particularly if rapid personalized feedback is available.

Conclusions: ESM enhances clinical practice and research. It is empowering, providing coownership of the process of diagnosis, treatment evaluation, and routine outcome measurement. Blended care, based on a mix of face-to-face and ESM-based outside-the-office treatment, may reduce costs and improve outcomes.

KEYWORDS

depression, ecological momentary assessment, patient-reported outcome, self-assessment, selfcare

\section{1 | INTRODUCTION}

The practice of mental health is changing rapidly, requiring new tools to involve patients in the process of diagnosis and treatment, and to provide perspectives of acceptance and sense of purpose. Two factors are particularly important. First, treatment models propose a more active and empowered role of patients, with active self-management and shared decision making as core elements (Huber et al., 2011). 
Self-monitoring is a main component of self-management, providing an opportunity for collaborative diagnosis and treatment evaluation, and forming the starting point for self-insight and initiation of change in patterns of experience and behavior. Second, the process of assessment and treatment in mental health care is becoming more personalized. Traditional diagnostic and guideline-based practice for the "average" patient is being complemented with more dynamic, personalized formulations of psychopathology as a within-person series of mental states that evolve over time, under the influence of daily life environments and the impact of mental states on each other, requiring personalized solutions. The fit of selected intervention strategies can be assessed, and personalized formulations reevaluated in an iterative monitoring process toward shared decision making.

In this article, we will discuss how the collection of intensive contextual mental state data, known as the experience sampling method (ESM) or ecological momentary assessment (EMA; Csikszentmihalyi, Larson, \& Prescott, 1977), in the form of an mHealth smartphone application, has the potential to become a mainstream instrument to support self-monitoring, personalized health care and the development of self-insight and avenues for personal change and acceptance of disabilities in clinical practice. Although ESM was initially used as a research tool in social psychology and the study of psychopathology, it was also found to have value in the management of (severe) mental illness (aan het Rot, Hogenelst, \& Schoevers, 2012; Delespaul, 1995; EbnerPriemer \& Trull, 2009; Myin-Germeys et al., 2009; Palmier-Claus et al., 2012; Walz, Nauta, \& aan het Rot, 2014). Smartphones and customized apps have dramatically simplified the user experience and reduced the logistic burden of data collection and analysis. ESM is now available as a free mHealth smartphone app in Apple App Store and Android Store (e.g., PsyMate, xSample, movisensXS, BeepMe, RealLife). Free availability makes it possible to use ESM in regular clinical practice. Although the multilevel analysis of ESM research data can be complex, even simple graphical feedback of ESM data can represent a source of substantial enrichment of clinical practice. By making use of the data at the personal and the descriptive level, testing $n=1$ clinical hypotheses about diagnosis, treatment, change, and acceptance becomes possible (Bak, Drukker, Hasmi, \& van Os, 2016; Delespaul, 1995).

\section{2 | THE PRACTICE OF ESM}

ESM is a structured data collection technique in which participants respond to randomly timed repeated assessments (up to around 10 times per day) over the course of time (up to around 10 days-with extensions of up to 1 year) while functioning within their natural setting (Csikszentmihalyi et al., 1977; Delespaul, 1995; Fig. 1). The sampling is signal-contingent, meaning that individuals respond to semirandom signals ("beeps'”-typically one random beep per 90-min slot). Data collection focusses on (i) emotions-items that reflect the broad dimensions of positive affect (PA; e.g., cheerful, relaxed, satisfied, happy) and negative affect (e.g., down, lonely, anxious, insecure); (ii) contexts-where, with whom, events; (iii) activities-doing what, (iv) food, alcohol, drugs, medication; (v) aspects of psychopathology psychotic phenomena, suicidality, craving, self-esteem; (vi) somatic
Mental state $1 \square$ Mental state 3

Mental state 2

Context 1

Mental state 4

Context 2

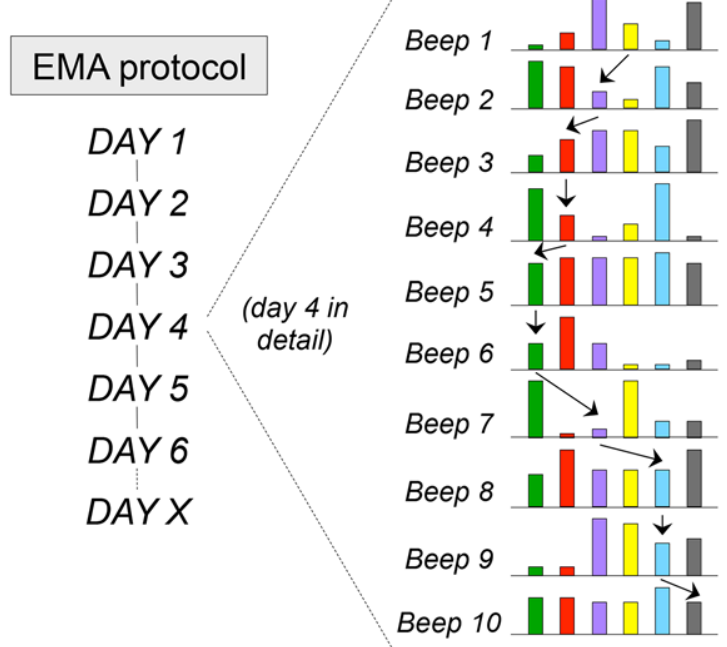

FIGURE 1 Principles of experience sampling methodology (ESM) or ecological momentary assessment (EMA)

Notes: At 10 random moments during the day, mental states (e.g., anxiety, low mood, paranoia, being happy) and contexts (stress, company, activity, drug use) are assessed. The arrows represent examples of prospectively analyzing the impact of mental states and contexts on each other over time, allowing for the construction of composite measures such as stress-sensitivity (impact of stress on negative affect), reward experience (impact of positive events on positive affect), or the autocorrelation (the impact of the mental state on itself from one moment to the other, resulting in more or less persistence over time).

symptoms (e.g., pain, fatigue, dizziness, tinnitus, etc.); and (vii) stressstressful momentary events, stress associated with momentary activity (e.g., "This activity is difficult for me," "I would prefer doing something else"), stress associated with momentary company (e.g., "I find being with these people pleasant[reversely coded to reflect stress]"). For use in routine clinical practice, a sampling scheme with eight random signals per day and no more than 30 items to rate is generally feasible (Delespaul, 1995). With adequate software, subjects can rate responses within $1 \mathrm{~min}$, only minimally disturbing the flow of normal daily routines. A sampling scheme of less than eight times per day yields insufficient measurements, given a normally $20-30 \%$ beep attrition in natural circumstances (Delespaul, 1995). Furthermore, care must be taken to include only items that can vary momentarily (e.g., "I am angry") rather than items reflecting trait, that do not vary momentarily ("I am clever").

ESM has a number of advantages (Delespaul, 1995). First, it gives the clinician insight in the contingencies of experience and behavior, based on prospective data. Second, ESM observations have, contrary to clinical interactions, ecological validity, reflecting real life variation in response to real life challenges. Third, ESM makes use of in-the-moment reports not subject to memory biases and "global evaluation" distortions. Fourth, although ESM requires considerable motivation on the part of the patient, this motivation likely correlates with motivation for change in the context of treatment. Given that this is 
an important clinical variable, ESM can be revealing, to both patient and attending clinician with respect to motivation for change. Fifth, ESM allows for a prospective, within-person approach to diagnosis and treatment, contrasting with the between-person, "average patient" approach of traditional evidence-based practice. Sixth, evidence indicates that ESM empowers patients to become actively involved in collecting data, pertinent to treatment and assessment, in their own environments, thus becoming minimally co-participant (Wichers et al., 2011) and possibly part-owner of the process of care (Simons et al., 2015).

Although ESM can be combined with a range of sensor-based data (movement, position, activity) and ambulatory physiological measures (e.g., salivary cortisol, heart rate, blood pressure, voiding behavior, etc.), more research is required on their added value to ESM ratings of experience and behavior. Furthermore, while a range of physiological measures can be measured in daily life, their relevance for mental health diagnosis and treatment remains to be established.

\section{CLINICAL APPLICATIONS OF ESM}

\subsection{From group-based data to $n=1$ predictions}

A local database with a large number of observations pertaining to different patient groups is helpful as a reference for the interpretation of clinical ESM data in individual patients. Next, a number of clinical applications of ESM will be illustrated using data from the ESM database that is being managed at Maastricht University (version 4.6). The database contains ESM studies that were conducted on different populations with comparable ESM lists, although not all ESM items were available in each group. Version 4.6 of the ESM database contains data on 276 healthy controls, 601 healthy twins from the general population, 178 relatives of patients with a psychotic disorder, 293 patients with psychotic disorder, 115 patients with depression, 129 patients with residual depression, and 106 individuals with variable levels of psychometric risk for psychotic disorder. We will show that ESM patterns at the group level are highly informative and form an attractive basis for testing hypotheses in single patient ESM data.

\subsection{Assessing psychopathology variation and reactivity across time and place}

Figures 2 and 3 display the simple variation over time and place of momentary "feeling low" in controls, individuals with residual depression, and individuals with depression. The graphs show clear differences in terms of severity, pattern of variation over time (Fig. 2), and pattern of reactivity as a function of place (Fig. 3). In controls, the mood item remains constant at low levels, showing little variation as a function of location. From individuals with residual depression to individuals with depression, "feeling low" is progressively more severe and showing progressively more diurnal variation. Furthermore, the data in the depressed groups show more reactivity as a function of location, with the greatest severity being associated with health care locations, as well as during transport.
Although the Figures 2 and 3 thus suggest clear and meaningful differences between groups, the interpretation of individual ESM data remains a challenge. Figure 4 shows individual trajectories of momentary variation of the mood item "feeling low," separately for each patient in the depression group. These individual trajectories show very substantial variation from beep to beep and day to day, between and within persons. Such variation nevertheless has a meaningful and clinically interpretable pattern within individuals, differing from other persons, and is not entirely random. Therefore, ESM allows for clinical inspection and interpretation of data at both the group and individual levels.

\subsection{Assessing dynamic system ability to bounce back from disturbance}

An emerging concept in psychopathology is the ability to bounce back given disturbance and impending mental decompensation in a dynamic system model of psychopathology (Odgers et al., 2009; Wichers, Groot, \& ESM-Merge Group, 2016). For example, alterations in mood may cause a person to perceive the environment as threatening or alien. Initially, the person may be able to "shake off" this impression of aberrant salience, indicating resilience and stability, with a rapid return of the altered mental state to baseline in the face of disturbing influences. However, in more advanced stages, the person may not rapidly return to the baseline mental state and progressively spend more and more time in the altered mental state of aberrant salience (Wigman et al., 2013). ESM data are suitable to capture this process of progressive loss of flexibility and ability to bounce back given system disturbance by plotting the autocorrelation of successive mental states. The autocorrelation of a mental state in ESM is the similarity between observations as a function of the time lag between them, or the tendency of the mental state to persist from one moment to the other over time (Wigman et al., 2013). In Figure 5a, controls have low variability in the ESM item indexing paranoia, therefore the autocorrelation function is low and not necessarily informative on the ability to bounce back from paranoid mental state deviations. In patient groups, ESM data are less ambiguous in this regard, allowing for interpretation of the autocorrelation. Thus, those with residual depression have altered bounce back ability (less rapid return to baseline), whereas individuals with psychotic disorder show paranoia inflexibility (Fig. 5a). Figure $5 \mathrm{~b}$ shows that from controls to residual depression to depression, there is a decrease in bounce back ability from mental states deviations characterized by anxiety. However, no such differences are seen for the item of "difficulty concentrating" (Fig. 5c), suggesting that alterations of mental state flexibility may occur independently across different mental states, and that there may be a "hierarchy" (within and between persons) in the level of volatility in emotions and experiences, ranging from extreme volatility to "trait"-like persistence. In addition, charting the autocorrelation as a function of resilience to "bounce back" from disturbance may inform on environmental or genetic risk factors, as shown in Figure $5 \mathrm{~d}$, which depicts altered capacity to bounce back from the mental state of anxiety as a function of parental divorce. Alterations in the ability to bounce back from disturbance 


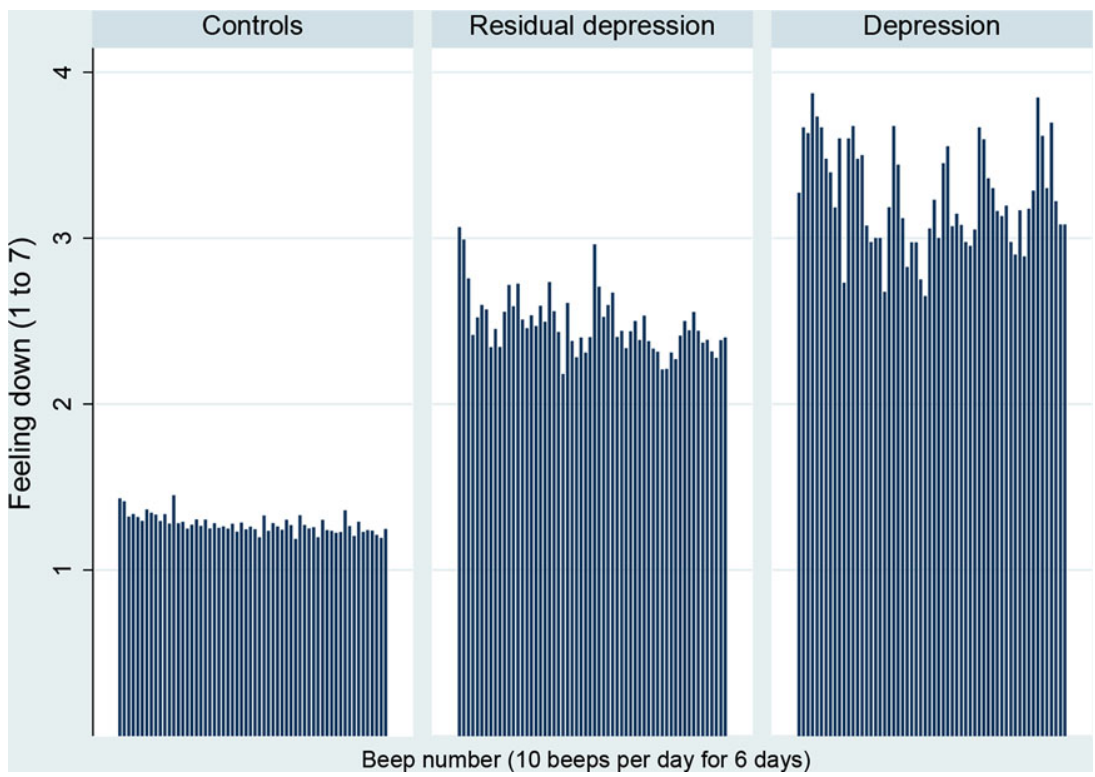

FIGURE 2 Momentary, beep-level self-reports (maximum of 60 beeps) of the mean of the ESM item "feeling down," collected over 6 days, in three samples of, respectively, controls ( $N=251, n=12,394$ beep moments), patients with residual depression ( $N=129, n=6,420$ beep moments), and depression ( $N=45, n=2,287$ beep moments)

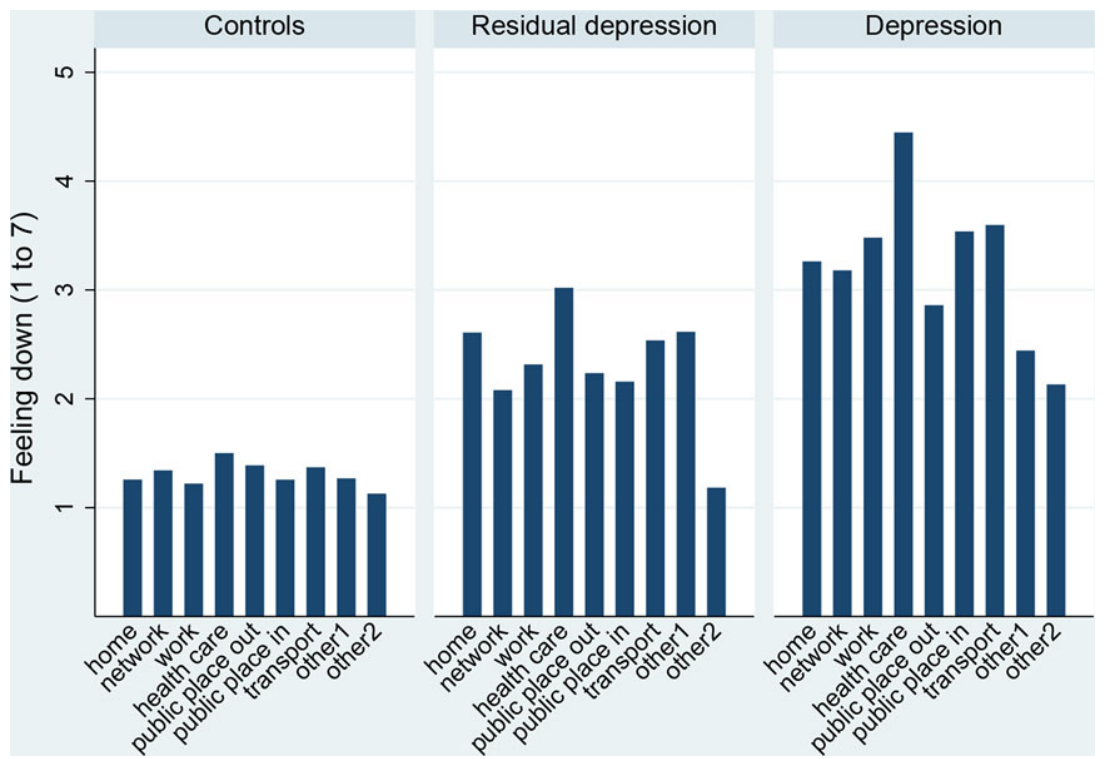

FIGURE 3 Self-reports of the ESM item "feeling down," collected over 6 days in daily life, summarized as mean level per location in three samples of controls ( $N=251, n=12,394$ beep moments), patients with residual depression ( $N=129, n=6,420$ beep moments), and depression ( $N=45, n=$ 2,287 beep moments)

can also be studied within individuals, particularly in longer ESM trajectories, as a function of treatment response and prediction of outcome (Wichers et al., 2016). Conversely, a greater autocorrelation in PA, that is, a greater level of momentary transfer of positive emotions, may be protective, as it was associated with a greater recovery rate and prevention of depressive episodes (Hohn et al., 2013). To date, however, lengthy ESM-based time series remain rare in the research literature.

\subsection{Assessing the impact of symptoms on each other}

The above example provides indirect evidence of how one mental state (low mood) affects another mental state (paranoia), increasing levels of low mood apparently giving rise to progressively higher levels of paranoia. However, ESM data also allow for a more direct examination of this process, by modeling the prospective relationships between mental states and symptoms. Given the fact that ESM data represent a time series, it is possible to examine the impact of, for 


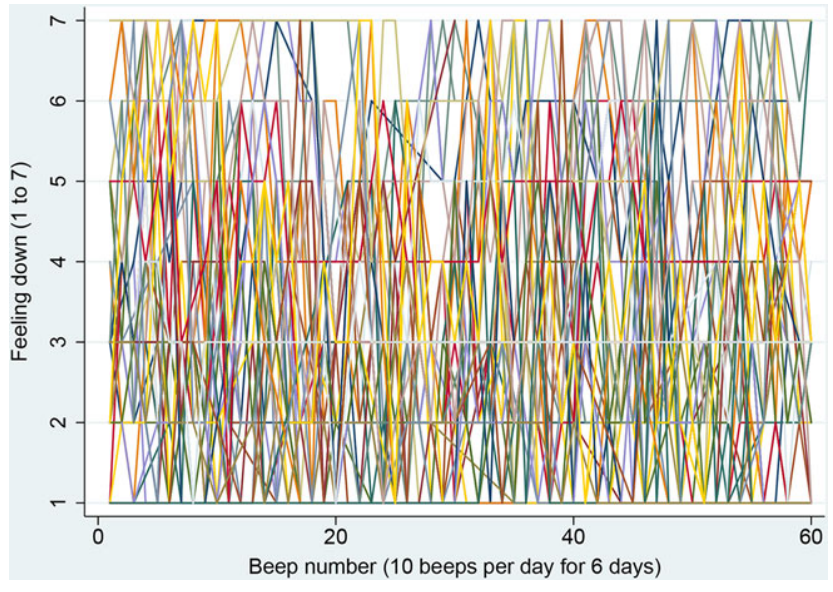

FIGURE 4 Trajectories of momentary $(n=1)$, beep-level ESM selfreports of "feeling down," collected over 6 days, in a sample of depressed patients ( $N=45, n=2,287$ beep moments)

example, the level of anxiety at the preceding beep (time point $t-1$ ) on low mood at the next beep (time point $t$ ). Similar analyses can be carried out at other levels of aggregation, for example, at day-level. These types of analyses have to take into account natural "breaks" in the data, avoiding, for example, that an ESM item pertaining to the first beep of one day is predicted by an ESM item pertaining to the last beep of the previous day. In Figure 6, prospective relationships are assessed between momentary anxiety and depression, and between momentary feeling happy, on the one hand, and anxiety and depression, on the other. In those with low momentary levels of depression at $t-1$, anxiety at $t-1$ drives the incidence of depression at $t$ in a dose-response fashion. Vice versa, momentary depression at $t-1$ drives incident anxiety at $t$. The two mental states can thus be said to mutually impact each other's momentary incidence in a reinforcing loop. In contrast, feeling happy at $t-1$ protects, in a dose-response fashion, against the onset of both anxiety and depression (Fig. 6). Dynamic prospective relationships between mental states and symptoms can be extended to a full network of mutually impacting momentary mental states, involving multiple symptoms (Borsboom, \& Cramer, 2013). Although betweenperson analyses are helpful to examine dynamics at the group-level, ESM allows for examination of within-person relationships and their impact on treatment. The concept of ESM clinical network analysis was recently introduced to describe the possibility of collecting ESM data for an extended period to help patients gain insight in the dynamics of the underlying psychopathology to decide which are the best connected points in the network where change likely will affect the most other symptoms and to assess the impact of treatment in the network (Bak et al., 2016). For example, Bak et al. (2016) showed the example of a person with disabling auditory hallucinations that were fuelled by a mutually reinforcing loop of paranoia and low mood, allowing for a more focused treatment approach.

\subsection{Assessing the impact of the environment}

One of the important advantages of ESM is the ability to link momentary measures of experience and behavior to self-reports of the envi- ronment. In Figure 7a, momentary reports of low mood as a function of activity stress (the rating of the momentary activity in terms of "I would rather do something else") are compared between a control group and a group with residual depression. The results show that low mood in controls has constant low values, not responding much to increases in activity stress, whereas low mood in individuals with residual depression appears to be much more reactive to the stressor. Similarly, momentary events rated as more pleasant neutralize momentary low mood in controls to a small degree, whereas a much greater protective effect is seen in patients with residual depression (Fig. 7b). This latter finding of greater reductions in negative affect following positive events is consistent with an independent report in the literature in patients with depression (Bylsma, Taylor-Clift, \& Rottenberg, 2011). The "buffering" effect of positive events is considerable: in Figure $7 \mathrm{~b}$, the level of low mood in the patient group at the highest level of pleasant event exposure approaches that of the control group. In other words, individuals with depression have higher levels of low mood, and are also more responsive to perceptions of environmental stress and environmental reward, which is in agreement with findings from other ESM studies (Audrain-McGovern, Wileyto, Ashare, Cuevas, \& Strasser, 2014; Myin-Germeys et al., 2003; Peeters, Nicolson, Berkhof, Delespaul, \& deVries, 2003). The origins of increased momentary mood reactivity in depression have been linked to genetic liability for depression (Peeters et al., 2003; M. Wichers et al., 2007) as well as to childhood trauma (Wichers et al., 2009), suggesting that ESM measures of reactivity can provide information on the mechanism whereby genes and environment confer vulnerability and resilience to depression. For example, one study found that in individuals with genetic liability for depression, the ability to generate positive emotions in response to the environment prevented the expression of genetic risk in low mood states (Wichers et al., 2007).

\section{6 | Assessing ecological cognition}

Contextual sensitivity is related to the cognitive ability to detect environmental changes. Environmental adaptation strategies or optimized coping assume that subjects are able to detect clues and use these in a learning process (in which PA and avoidance of stress function as rewards). There is a need to understand whether the cognitive skills are influenced by the changing environment, or by the way individuals assess these skills in daily life. It is therefore important to understand changes in cognition within the same time frame as changes in emotions and context. The assessment of variation in cognitive function in daily life is a challenge. The first reason is that the tests used in traditional cross-sectional assessments often rely on repeated trials lasting some minutes. This is difficult to implement in daily life given the time restraints of ESM-disruption should be restricted to 1-2 min maximally. Second, cognitive tests need contextual standardization to be reliable. The circumstances of the daily life assessments are highly variable and make it difficult to fully focus on the test. Third, ESM measurements are typically replicated 10 times each day for days or weeks. Such a sampling scheme requires a battery of parallel tests with limited training effects. More knowledge is required to design tests that can be used to assess different dimensions of cognitive functioning 
in daily life. Currently, pilots are being conducted to test the implementation of short cognitive tasks in ESM. These pilot studies are related to memory (i.e., recall and recognition, both with and without intermediate tasks), concentration (i.e., coding tasks or elementary computations), reasoning (i.e., mathematical problem solving), and planning, in addition to tests that are related to cognitive biases and social cognition such as "jumping to conclusions" and "theory of mind."
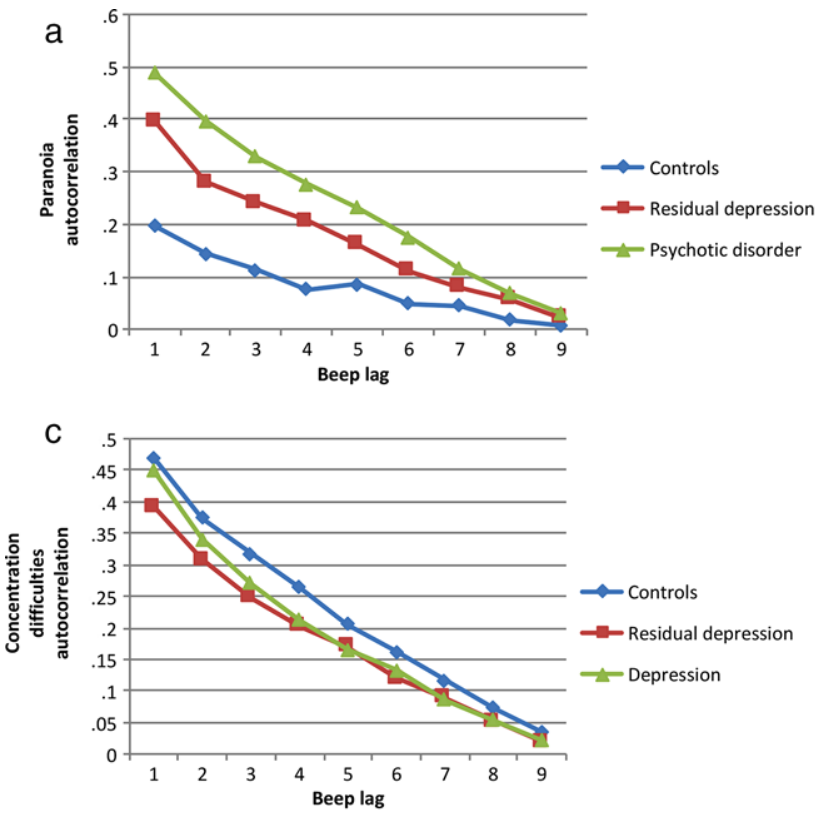

\subsection{ESM as a tool for positive emotion enhancement}

Given ecological validity, low cost, and smartphone availability, there is increasing interest in using ESM in the context of trials (Verhagen, Hasmi, Drukker, van Os, \& Delespaul, 2016). For example, there is evidence that monotherapy with psychotropic medication may not constitute optimal care for common mental disorders. Instead, treatment combining medication with some form of behav-
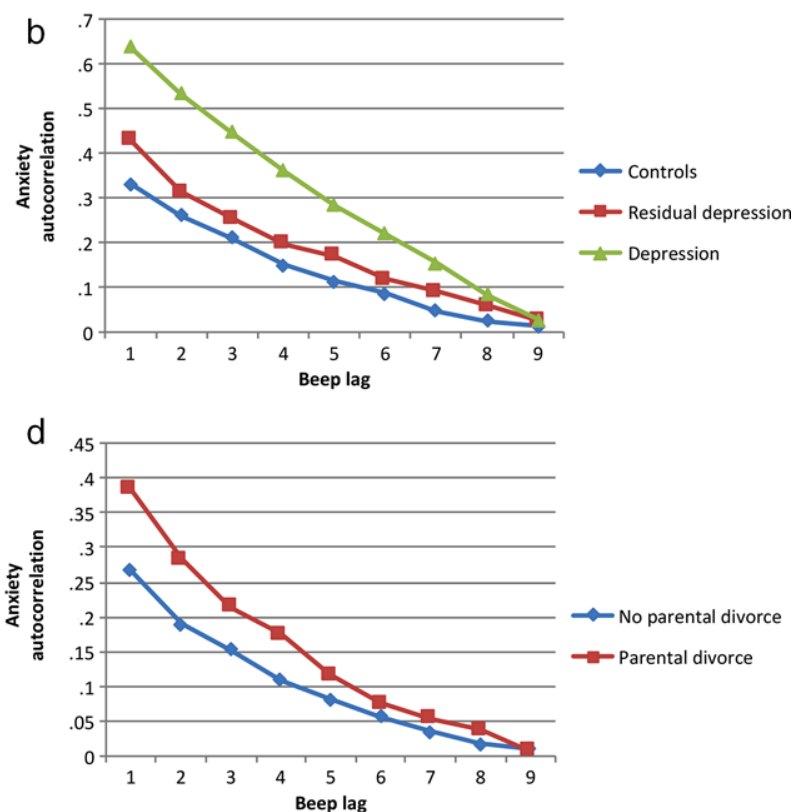

FIGURE 5 (a) Autocorrelations over successive lags of the ESM mental state of feeling "suspicious" (paranoia), collected over 6 days (10 beeps per day, nine lags), in three samples of controls ( $N=212, n=10,260$ beep moments), patients with residual depression ( $N=129, n=6,412$ beep moments) and psychotic disorder ( $N=293, n=12,400$ beep moments). (b) Autocorrelations over successive lags of the ESM mental state of feeling "anxious," collected over 6 days (10 beeps per day, nine lags), in three samples of controls ( $N=276, n=13,513$ beep moments), patients with residual depression ( $N=129, n=6,420$ beep moments), and depression ( $N=114, n=5,324$ beep moments). (c) Autocorrelations over successive lags of the ESM mental state of "difficulties concentrating," collected over 6 days (10 beeps per day, nine lags), in three samples of controls ( $N=$ $276, n=13,199$ beep moments), patients with residual depression ( $N=129, n=6,483$ beep moments), and depression ( $N=115, n=5,329$ beep moments). (d) Autocorrelations over successive lags of the ESM mental state of "feeling anxious," collected over 5 days (10 beeps per day, nine lags) in a general population sample of twins of whom $N=525$ ( $n=18,991$ beeps) reported no parental divorce and $N=51$ ( $n=1,852$ beeps) reported parental divorce

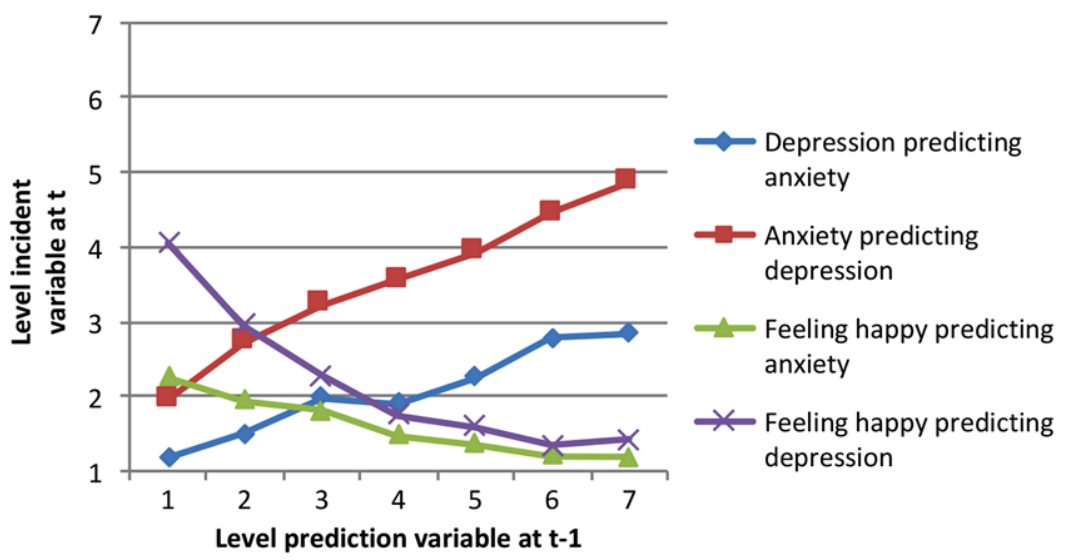

FIGURE 6 Predicting the incidence (i.e., mean level of mood state at $t$ in those with the lowest score of that mood state at beep $t-1$ ), as a function of the level of another mood state at beep $t-1$, in a sample of individuals with residual depression ( $N=223, n=10,582$ beeps). For example, in those with the lowest score of "feeling down" at $t-1$, higher levels of anxiety at $t-1$ predict progressively greater levels of feeling down at $t$, and higher level of feeling happy at $t-1$ predict progressively lower scores of feeling down at $t$ 

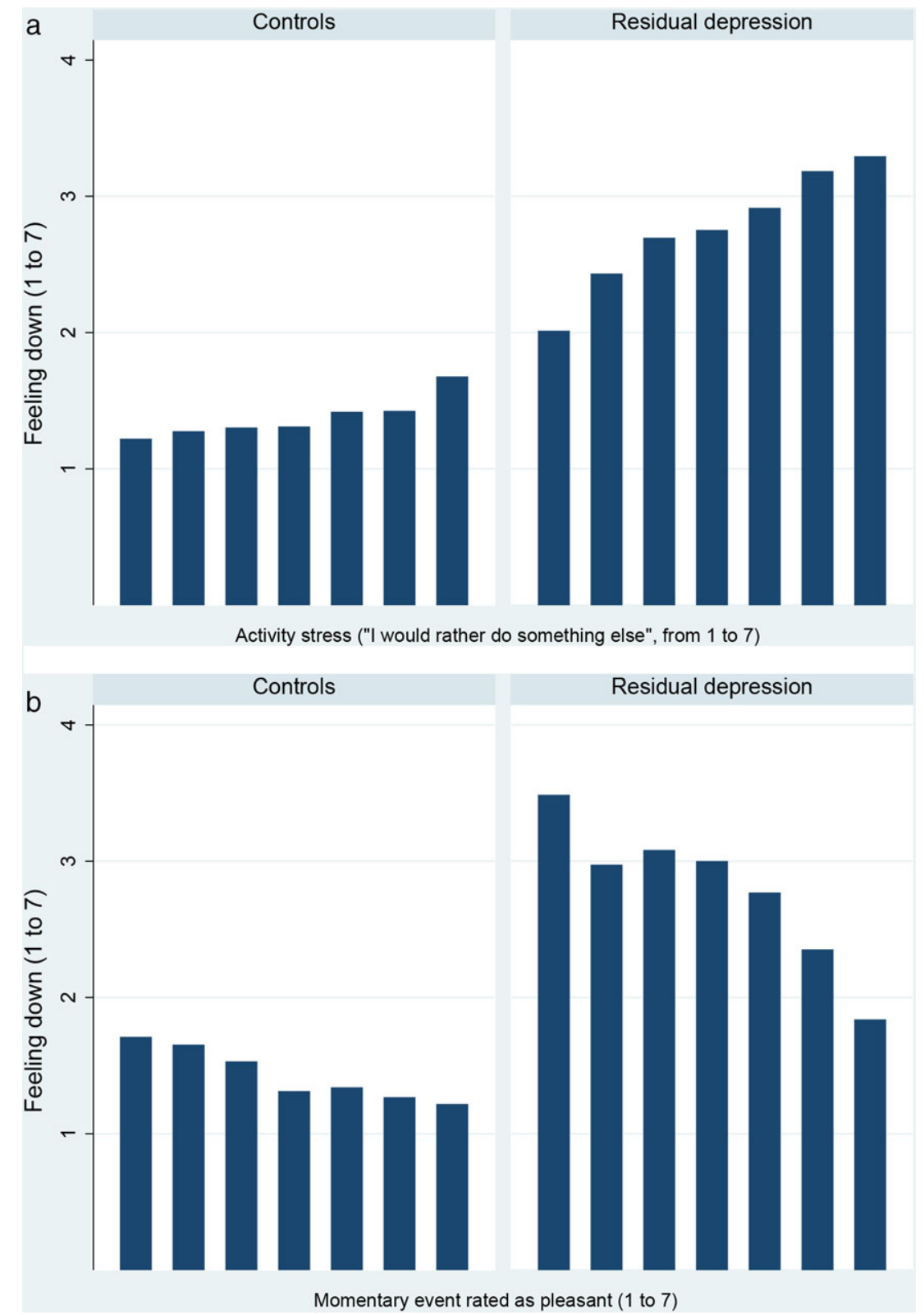

FIGURE 7 (a) Mean of self-reported ESM item "feeling down," collected over 6 days in daily life, summarized over increasing levels of activityrelated stress in a sample of controls $(N=212, n=10,142$ beep moments) and a sample of patients with residual depression ( $N=129, n=6,425$ beep moments). (b) Mean of self-reported ESM item "feeling down," collected over 6 days in daily life, summarized over increasing levels of how pleasant momentary events were rated of in a sample of controls $(N=212, n=9,777$ beep moments) and a sample of patients with residual depression ( $N=$ $129, n=6,250$ beep moments)

ioral intervention appears more effective than treatment with medication alone (Cuijpers et al., 2014). Given the fact that (i) behavioral interventions, complex or simple, appear to have similar effect sizes in the treatment of common mental disorder (Cuijpers, Donker, van Straten, Li, \& Andersson, 2010) and (ii) simple mHealth selfmonitoring interventions can add to the treatment of mental disorders (Berrouiguet, Baca-Garcia, Brandt, Walter, \& Courtet, 2016), there is interest in the concept of adding self-monitoring interventions to medication in the treatment of common mental disorder as a strategy to enhance the effect that would have been obtained with medication alone. A recent randomized trial added an ESM-based self-monitoring intervention, combined with feedback on how to improve patterns of generating PA in daily life, based on ESM self-monitoring data, to medication in patients treated for depression. This type of feedback can consist simply of systematically examining instances of positive emotions in daily life, and discussing strategies to increase the frequency of such moments and/or increase the persistence of positive emotions in daily life. Patients receiving the combination of medication and the ESM-based self-monitoring and positive emotion enhancement tool did better than patients receiving medication alone (Kramer et al., 2014). These data suggest that ESM self-monitoring and positive emotion feedback paradigms may be added routinely to 


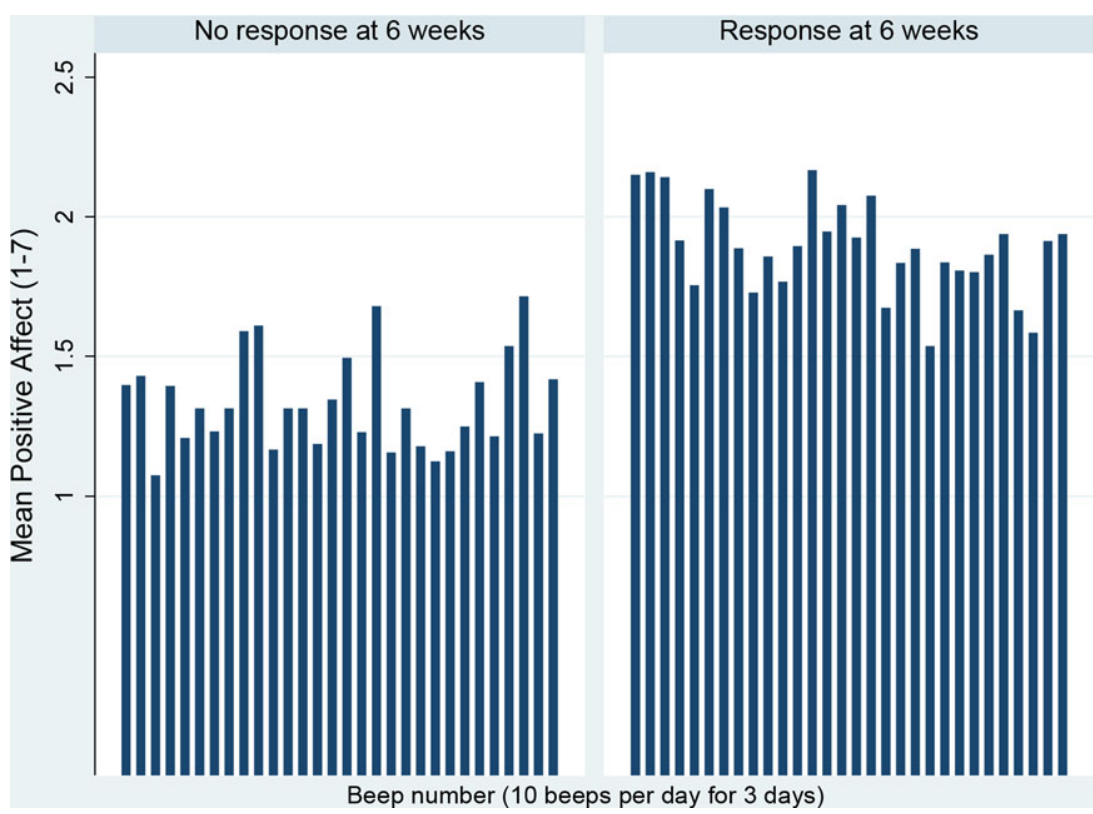

FIGURE 8 ESM momentary levels of positive affect (PA-the mean of eight momentary positive emotions) in 26 patients with depression during the first 3 days of imipramine treatment, stratified by responder status ( $50 \%$ reduction in HAMD) at 6 weeks $(n=26,578$ beep moments)

treatment with psychotropic medication in clinical practice. It has been suggested that antidepressant medication may work by facilitating the process of practice-induced plasticity (Sterling, 2014). ESM, as a context-sensitive tool to help individuals optimizing environmental interactions and coping (Lardinois et al., 2007), may be well placed to enhance the practice required for the plasticity-enhancing effect of antidepressants. Momentary assessment interventions may be used to enhance nonpharmacological interventions as well. For example, Depp et al. (2015) showed that adding an ecological momentary intervention targeting self-management of mood symptoms increased the effect of a brief psychoeducation on depressive symptoms. However, results also showed that the benefits only lasted as long as the mobile intervention was ongoing (Depp et al., 2015). Batink et al. (2016) introduced an ESM-based mHealth paradigm as an add-on intervention to help patients practice with acceptance and commitment therapy (ACT) in their daily lives. The intervention proved practicable and feasible for patients, with high levels of adherence. Although no short-term effects could be demonstrated, the authors hypothesized that effects of ACT may take longer to transpire (Batink et al., 2016).

\subsection{ESM as a tool for tapering and dose finding of psychotropic medication}

Symptoms of anxiety, depression, and psychosis are sensitive to a range of pharmacological interventions. There are considerable challenges in finding the right dose for a given individual and there is widespread variation in the level of difficulties patients experience when coming off psychotropic medications. There is growing awareness that personalized dosing of psychotropic medication has beenand still is-a neglected area in clinical psychiatry, as is the personalized approach toward reducing or stopping psychotropic medication.
ESM studies have shown that intensive sampling of emotions and context represents a sensitive tool to pick up the early effects of changing dose and reducing medications (Bak et al., 2016; Barge-Schaapveld \& Nicolson, 2002; Lataster et al., 2011a, 2011b; Wichers et al., 2009), as well as picking up early changes after dose reduction that may predict imminent relapse (Wichers et al., 2016). Given the potential of ESM to empower the patient to cocreate diagnosis and treatment evaluation, as well as the observed synergistic effects between ESM as a self-management tool and psychotropic medication, described earlier, a case could be made for the routine use of ESM when initiating or reducing psychotropic medication. For example, when starting antidepressant medication, ESM in the first week can pick up signs of early response in the form of increases in the ability to use natural rewards (variation in positive emotions after positive events in daily life; Wichers et al., 2009); or reduction of antipsychotic medication can be monitored with ESM for alterations in subtle experiences of aberrant salience as a sign of dopamine supersensitivity syndrome (Murray et al., 2016).

In Figure 8, we show descriptive ESM data of early response to an antidepressant in a randomized, placebo-controlled trial of imipramine in a group of patients with depressive disorder described previously (Barge-Schaapveld, Nicolson, van der Hoop, \& De Vries, 1995; van Os, Delespaul, Barge, \& Bakker, 2014; Wichers et al., 2009). Only participants randomized to the imipramine group with valid ESM data and outcomes at 6 weeks are shown $(n=26)$. Response at 6 weeks was defined as a reduction of $50 \%$ or more in baseline Hamilton Depression Rating Scale (HAMD) score. Figure 8 shows the ESM momentary levels of PA, stratified by future responder status, during the first 3 days of imipramine treatment. Future responders have higher levels of PA (Fig. 8). Thus, ESM trajectories may index information on future response in routine clinical practice. 

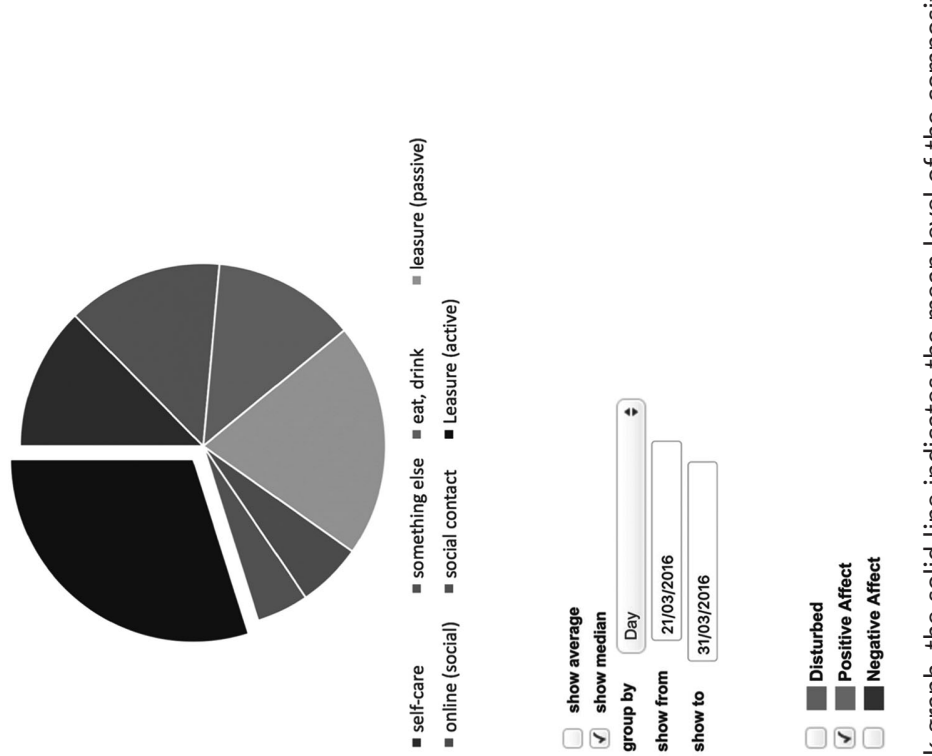

:

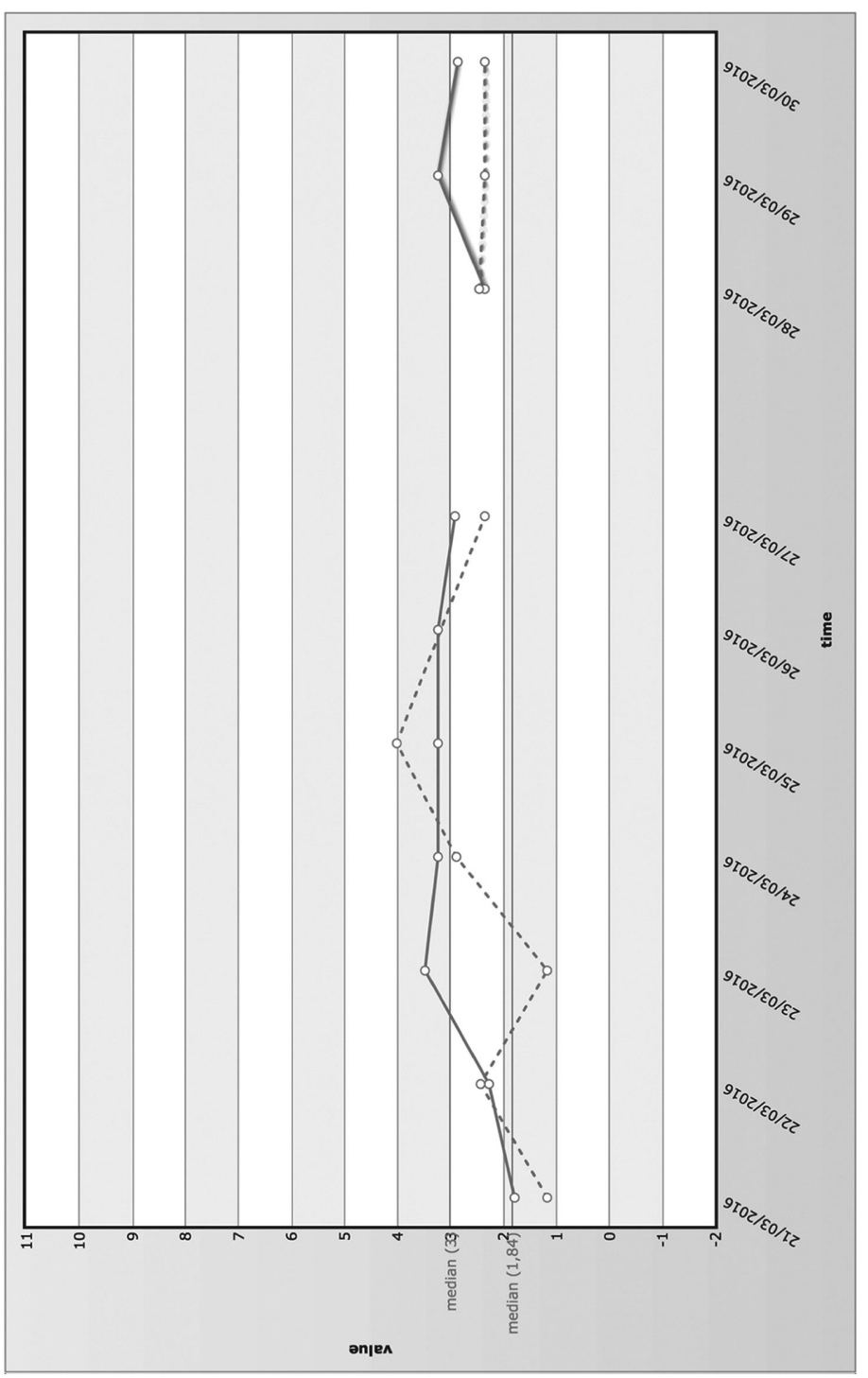

胥

ये

당

ह

苋 咅

范 몽

을

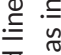

$\frac{\bar{d}}{\frac{0}{4}}$

$\stackrel{0}{\frac{0}{4}}$

就

总

궁

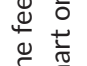

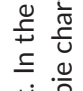

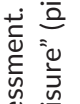

$\stackrel{\frac{\pi}{\omega}}{0}$

范范

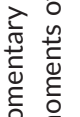

हे

है

인

这嵒

递

需

ग $\frac{10}{0}$

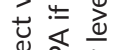

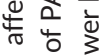

\% 응

语这离

要

$\stackrel{ \pm .}{.}$

品.

ठ 훠

둥

o d

弟它

吾

ष्ष 든

절

老造

宅

ه $\frac{4}{\sigma}$

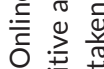

a

u․․

苟 


\subsection{ESM as a tool for collaborative care in somatic settings}

Experiential and behavioral outcomes are central in the diagnosis and treatment of a range of stress-related somatic syndromes, ranging from Alzheimer and Parkinson's disease to irritable bowel syndrome, pain, tinnitus, Chronic Obstructive Pulmonary Disease (COPD), diabetes, and urinary incontinence. ESM studies show that mood states and contextual factors interact with specific experiential outcomes in these disorders, and that ESM can facilitate management and collaborative care approaches in the hospital (Broen et al., 2016; Bruehl, Liu, Burns, Chont, \& Jamison, 2012; Fischer et al., 2016; Leue et al., 2017; Mujagic et al., 2014, 2015; van Knippenberg et al., 2016; Vrijens et al., 2015). For example, deep brain stimulation is used in Parkinson's disease, however, it is often very difficult to assess subtle experiential, cognitive, and behavioral side effects associated with this treatment. A pilot study has shown that ESM can be used to assess both the mental and the motor symptoms in Parkinson's disease (Broen et al., 2016); follow-up work is required to assess the effects of deep brain stimulation in this condition. Similarly, the effects of treatment on irritable bowel syndrome are very difficult to capture using conventional methods; it has been suggested that ESM may be used routinely in randomized trials in this disorder (Mujagic et al., 2015).

\subsection{0 | ESM as a form of routine outcome monitoring with a focus on positive mood states}

There is consistent evidence that the impact of both pharmacological and nonpharmacological treatments is mediated by enhancing positive emotions, more than reduction of negative emotions, although interventions can be shown to also impact negative emotions and reactivity to negative events (Silk et al., 2016). In a randomized controlled trial of antidepressants, improvement in the ability to generate positive emotions differentiated responders and nonresponders to antidepressants medication (Wichers et al., 2009). Similarly, in another investigation, it was shown that early improvement in ESM-based positive emotions was a better predictor of outcome than improvement in momentary negative emotions (Geschwind et al., 2011). Trial evidence indicates that mindfulness training is effective for the treatment of depression and anxiety (Hofmann, Sawyer, Witt, \& Oh, 2010) and for preventing depression relapse (Kuyken et al., 2015). In a randomized trial of mindfulness training in depression, the underlying emotional mechanism was investigated with ESM. The results revealed that, similar to antidepressant medication, clinical improvement was mediated by greater ability to generate momentary positive emotions, as well as longer momentary persistence of positive emotions (Geschwind, Peeters, Drukker, van Os, \& Wichers, 2011). Another study reported evidence that the effect of physical exercise on mood is also mediated by changes in positive emotions (Wichers et al., 2012). The importance of ESM measures of positive emotions was further shown by a study reporting that experienced PA, even over a single day, displayed a graded relationship with survival in elderly persons that was not caused by baseline health status or other covariates (Steptoe, \& Wardle, 2011). Thus, positive emotions appear to play a crucial role in facilitating the mobilization of resilience in the face of adversity, with important consequences for coping and health (Tugade, Fredrickson, \& Barrett, 2004).

Given the importance of positive emotions, it has been proposed that ESM is routinely used in clinical practice, not only to improve diagnosis, empower patients, or enhance the effects of medication, but also as a means to collect routine outcome data that, contrary to symptom-based measures, yield insight in daily life adaptation (BargeSchaapveld et al., 1995) and changes in resilience in the form of positive emotions. One study found that of the different measures in ESM that can be used as routine outcome measurement (ROM), changes in positive emotions were the most sensitive to change, suggesting this dimension represents a suitable measure for ROM in mental health services (van Os et al., 2014).

If ESM is used routinely in a specific mental health treatment setting, it is possible to generate, using anonymized patient data, groupbased reference data of ESM patterns of emotions and behavior, as described in this article, against which ESM trajectories pertaining to individual patients can be interpreted, similar to the current analyses (Delespaul, 2015). In the foreseeable future, machine learning techniques may be used to help test hypotheses in single patients against a large population base of ESM reference data (Strauss, Peguero, \& Hirst, 2013).

\section{4 | STARTING TO USE ESM IN CLINICAL PRACTICE}

To start using ESM in clinical practice, one may commence with 5-day periods of ESM (eight beeps per day) at intake and after 6 weeks of treatment. At both baseline (diagnosis) and after 6 weeks (treatment response), clinician and patient can discuss the online feedback pattern of emotions and reactivity, as shown in the figure for the PsyMate app (Fig. 9). In addition, the clinician can encourage the patient to engage in ESM over the entire 6-week period at a rate of, for example, 3-4 days of ESM per week. ESM can then be combined with a focus on PA and a simple program aimed at enhancing frequency and persistence of PA in daily life. In addition, in PsyMate, aspects of acceptance and commitment and mindfulness exercises can be programmed in the time series (Batink et al., 2016), thus providing an opportunity to combine pharmacological or psychological treatment with mHealth ACT or mindfulness-based exercises.

\section{5 | CONCLUSION}

ESM is of low cost and high impact. Given widespread availability of personal digital devices, intensive data collection based on ESM is now sufficiently practicable to allow widespread use in psychiatry and indeed medicine. ESM is empowering, providing co-ownership of the process of diagnosis, treatment evaluation, and patient-reported ROM. Blended care, based on a mix of face-to-face and ESM-based outside-the-office treatment, has the potential to reduce costs and 
improve outcomes. ESM makes it possible to develop insight into previous implicit patterns of thought, experience, and behavior, particularly if rapid personalized feedback is available. ESM-based selfmonitoring and feedback can enhance resilience by strengthening the capacity to use natural rewards. Personalized trajectories of starting or stopping medication can be more easily initiated and predicted if sensitive feedback data are available in real time. In addition, personalized trajectories of symptoms, cognitive abilities, symptoms impacting on other symptoms, the mental capacity to "bounce back" from dynamic system disturbance and patterns of environmental reactivity yield uniquely personal data to support shared decision making and prognostication in clinical practice.

\section{ACKNOWLEDGMENTS}

U.R. is supported by a Veni grant from the Netherlands Organisation for Scientific Research (grant no. 451-13-022). This study is supported in part by a grant from the Weijerhorst Stichting and the European Community's Seventh Framework Program under grant agreement no. HEALTH-F2-2009-241909 (Project EU-GEI).

\section{CONFLICT OF INTEREST}

The authors report no conflict of interest.

\section{REFERENCES}

aan het Rot, M., Hogenelst, K., \& Schoevers, R. A. (2012). Mood disorders in everyday life: A systematic review of experience sampling and ecological momentary assessment studies. Clinical Psychology Review, 32(6), 510-523. Retrieved from https://doi.org/10.1016/j.cpr.2012.05.007

Audrain-McGovern, J., Wileyto, E. P., Ashare, R., Cuevas, J., \& Strasser, A. A. (2014). Reward and affective regulation in depression-prone smokers. Biological Psychiatry, 76(9), 689-697. Retrieved from https://doi.org/ 10.1016/j.biopsych.>2014.04.018

Bak, M., Drukker, M., Hasmi, L., \& van Os, J. (2016). An $n=1$ clinical network analysis of symptoms and treatment in psychosis. PLoS One, 11(9), e0162811. Retrieved from https://doi.org/10.1371/journal. pone.0162811

Barge-Schaapveld, D. Q., \& Nicolson, N. A. (2002). Effects of antidepressant treatment on the quality of daily life: An experience sampling study. Journal of Clinical Psychiatry, 63(6), 477-485.

Barge-Schaapveld, D. Q., Nicolson, N. A., van der Hoop, R. G., \& De Vries, M. W. (1995). Changes in daily life experience associated with clinical improvement in depression. Journal of Affective Disorders, 34(2), 139154.

Batink, T., Bakker, J., Vaessen, T., Kasanova, Z., Collip, D., van Os, J., ... Peeters, F. (2016). Acceptance and commitment therapy in daily life training: A feasibility study of an mHealth intervention. JMIR mHealth uHealth, 4(3), e103. Retrieved from https://doi.org/10.2196/ mhealth.5437

Berrouiguet, S., Baca-Garcia, E., Brandt, S., Walter, M., \& Courtet, P. (2016). Fundamentals for future mobile-health (mHealth): A systematic review of mobile phone and web-based text messaging in mental health. Journal of Medical Internet Research [Electronic Resource], 18(6), e135. Retrieved from https://doi.org/10.2196/jmir.5066

Borsboom, D., \& Cramer, A. O. (2013). Network analysis: An integrative approach to the structure of psychopathology. Annual Review of Clinical Psychology, 9, 91-121. Retrieved from https://doi.org/ 10.1146/annurev-clinpsy-050212-185608
Broen, M. P., Marsman, V. A., Kuijf, M. L., Van Oostenbrugge, R. J., van Os, J., \& Leentjens, A. F. (2016). Unraveling the relationship between motor symptoms, affective states and contextual factors in Parkinson's disease: A feasibility study of the experience sampling method. PLoS One, 11(3), e0151195. Retrieved from https://doi.org/10.1371/ journal.pone.0151195

Bruehl, S., Liu, X., Burns, J. W., Chont, M., \& Jamison, R. N. (2012). Associations between daily chronic pain intensity, daily anger expression, and trait anger expressiveness: An ecological momentary assessment study. Pain, 153(12), 2352-2358. Retrieved from https://doi.org/ 10.1016/j.pain.2012.08.001

Bylsma, L. M., Taylor-Clift, A., \& Rottenberg, J. (2011). Emotional reactivity to daily events in major and minor depression. Journal of Abnormal Psychology, 120(1), 155-167. Retrieved from https://doi.org/10.1037/ a0021662

Csikszentmihalyi, M., Larson, R., \& Prescott, S. (1977). The ecology of adolescent activity and experience. Journal of Youth and Adolescence, 6(3), 281-294. Retrieved from https://doi.org/10.1007/BF02138940

Cuijpers, P., Donker, T., van Straten, A., Li, J., \& Andersson, G. (2010). Is guided self-help as effective as face-to-face psychotherapy for depression and anxiety disorders? A systematic review and metaanalysis of comparative outcome studies. Psychological Medicine, 40(12), 1943-1957. Retrieved from https://doi.org/S0033291710000772 [pii] https://doi.org/10.1017/S0033291710000772

Cuijpers, P., Sijbrandij, M., Koole, S. L., Andersson, G., Beekman, A. T., \& Reynolds, C. F., 3rd (2014). Adding psychotherapy to antidepressant medication in depression and anxiety disorders: A meta-analysis. World Psychiatry, 13(1), 56-67. Retrieved from https://doi.org/10.1002/ wps.20089

Delespaul, P. (1995). Assessing schizophrenia in daily life: The experience sampling method (Ph.D. Thesis). Maastricht University Medical Centre, Maastricht.

Delespaul, P. (2015). Routine outcome measurement in the NetherlandsA focus on benchmarking. International Review of Psychiatry (Abingdon, England), 27(4), 320-328. Retrieved from https://doi.org/10.3109/ 09540261.2015 .1045408

Depp, C. A., Ceglowski, J., Wang, V. C., Yaghouti, F., Mausbach, B. T., Thompson, W. K., \& Granholm, E. L. (2015). Augmenting psychoeducation with a mobile intervention for bipolar disorder: A randomized controlled trial. Journal of Affective Disorders, 174, 23-30. Retrieved from https://doi.org/10.1016/j.jad.2014.10.053

Ebner-Priemer, U. W., \& Trull, T. J. (2009). Ecological momentary assessment of mood disorders and mood dysregulation. Psychological Assessment, 21(4), 463-475. Retrieved from https://doi.org/10.1037/ a0017075

Fischer, S., Doerr, J. M., Strahler, J., Mewes, R., Thieme, K., \& Nater, U. M. (2016). Stress exacerbates pain in the everyday lives of women with fibromyalgia syndrome-The role of cortisol and alpha-amylase. Psychoneuroendocrinology, 63, 68-77. Retrieved from https://doi.org/ 10.1016/j.psyneuen.2015.09.018

Geschwind, N., Nicolson, N. A., Peeters, F., van Os, J., Barge-Schaapveld, D., \& Wichers, M. (2011). Early improvement in positive rather than negative emotion predicts remission from depression after pharmacotherapy. European Neuropsychopharmacology, 21(3), 241-247. Retrieved from https://doi.org/10.1016/j.euroneuro.2010.11.004

Geschwind, N., Peeters, F., Drukker, M., van Os, J., \& Wichers, M. (2011). Mindfulness training increases momentary positive emotions and reward experience in adults vulnerable to depression: A randomized controlled trial. Journal of Consulting and Clinical Psychology, 79(5), 618628. Retrieved from https://doi.org/10.1037/a0024595

Hofmann, S. G., Sawyer, A. T., Witt, A. A., \& Oh, D. (2010). The effect of mindfulness-based therapy on anxiety and depression: A meta-analytic 
review. Journal of Consulting and Clinical Psychology, 78(2), 169-183. Retrieved from https://doi.org/10.1037/a0018555

Hohn, P., Menne-Lothmann, C., Peeters, F., Nicolson, N. A., Jacobs, N., Derom, C., ... Wichers, M. (2013). Moment-to-moment transfer of positive emotions in daily life predicts future course of depression in both general population and patient samples. PLoS One, 8(9), e75655. Retrieved from https://doi.org/10.1371/journal.pone.0075655

Huber, M., Knottnerus, J. A., Green, L., van der Horst, H., Jadad, A. R., Kromhout, D., ... Smid, H. (2011). How should we define health? BMJ (Clinical Research Edition), 343. Retrieved from https://doi.org/ 10.1136/bmj.d4163

Kramer, I., Simons, C. J., Hartmann, J. A., Menne-Lothmann, C., Viechtbauer, W., Peeters, F., ... Wichers, M. (2014). A therapeutic application of the experience sampling method in the treatment of depression: A randomized controlled trial. World Psychiatry, 13(1), 68-77. Retrieved from https://doi.org/10.1002/ wps. 20090

Kuyken, W., Hayes, R., Barrett, B., Byng, R., Dalgleish, T., Kessler, D., ... Byford, S. (2015). Effectiveness and cost-effectiveness of mindfulnessbased cognitive therapy compared with maintenance antidepressant treatment in the prevention of depressive relapse or recurrence (PREVENT): A randomised controlled trial. Lancet, 386(9988), 63-73. Retrieved from https://doi.org/10.1016/S0140-6736(14)62222-4

Lardinois, M., Myin-Germeys, I., Bak, M., Mengelers, R., van Os, J., \& Delespaul, P. A. (2007). The dynamics of symptomatic and nonsymptomatic coping with psychotic symptoms in the flow of daily life. Acta Psychiatrica Scandinavica, 116(1), 71-75.

Lataster, J., Myin-Germeys, I., Wichers, M., Delespaul, P. A., van Os, J., \& Bak, M. (2011a). Psychotic exacerbation and emotional dampening in the daily life of patients with schizophrenia switched to aripiprazole therapy: A collection of standardized case reports. Therapeutic Advances in Psychopharmacology, 1(5), 145-151. Retrieved from https://doi.org/10.1177/2045125311419552

Lataster, J., van Os, J., de Haan, L., Thewissen, V., Bak, M., Lataster T., ... Myin-Germeys, I. (2011b). Emotional experience and estimates of D2 receptor occupancy in psychotic patients treated with haloperidol, risperidone, or olanzapine: An experience sampling study. Journal of Clinical Psychiatry, 72(10), 1397-1404. Retrieved from https://doi.org/10.4088/JCP.09m05466yel

Leue, C., Kruimel, J., Vrijens, D., Masclee, A., van Os, J., \& van Koeveringe, G. (2017). Functional urological disorders: A sensitized defence response in the bladder-gut-brain axis. Nature Reviews Urology, 14(3), 153-163. Retrieved from https://doi.org/10.1038/nrurol.2016.227

Mujagic, Z., Leue, C., Vork, L., Lousberg, R., Hesselink, M., Van Os, J., ... Kruimel, J. (2014). IBS and over-reporting of abdominal pain in retrospective questionnaires: Advantages of experience sampling method as new digital tool in symptom measurement. Neurogastroenterology and Motility, 26, 2-3.

Mujagic, Z., Leue, C., Vork, L., Lousberg, R., Jonkers, D. M., Keszthelyi, D., .. . Kruimel, J. W. (2015). The experience sampling method-a new digital tool for momentary symptom assessment in IBS: An exploratory study. Neurogastroenterology and Motility, 27(9), 1295-1302. Retrieved from https://doi.org/10.1111/nmo.12624

Murray, R. M., Quattrone, D., Natesan, S., van Os, J., Nordentoft, M., Howes, O., ... Taylor, D. (2016). Should psychiatrists be more cautious about the long-term prophylactic use of antipsychotics? British Journal of Psychiatry, 209(5), 361-365. Retrieved from https://doi.org/ 10.1192/bjp.bp.116.182683

Myin-Germeys, I., Oorschot, M., Collip, D., Lataster, J., Delespaul, P., \& van Os, J. (2009). Experience sampling research in psychopathology: Opening the black box of daily life. Psychological Medicine, 39(9), 1533-1547. Retrieved from https://doi.org/10.1017/S0033291708004947
Myin-Germeys, I., Peeters, F., Havermans, R., Nicolson, N. A., DeVries, M. W., Delespaul, P., \& Van Os, J. (2003). Emotional reactivity to daily life stress in psychosis and affective disorder: An experience sampling study. Acta Psychiatrica Scandinavica, 107(2), 124-131.

Odgers, C. L., Mulvey, E. P., Skeem, J. L., Gardner, W., Lidz, C. W., \& Schubert, C. (2009). Capturing the ebb and flow of psychiatric symptoms with dynamical systems models. American Journal of Psychiatry, 166(5), 575582. Retrieved from https://doi.org/10.1176/appi.ajp.2008.08091398

Palmier-Claus, J. E., Ainsworth, J., Machin, M., Barrowclough, C., Dunn, G., Barkus, E., ... Lewis, S. W. (2012). The feasibility and validity of ambulatory self-report of psychotic symptoms using a smartphone software application. BMC Psychiatry [Electronic Resource], 12, 172. Retrieved from https://doi.org/10.1186/1471-244X-12-172

Peeters, F., Nicolson, N. A., Berkhof, J., Delespaul, P., \& deVries, M. (2003). Effects of daily events on mood states in major depressive disorder. Journal of Abnormal Psychology, 112(2), 203-211.

Silk, J. S., Tan, P. Z., Ladouceur, C. D., Meller, S., Siegle, G. J., McMakin, D. L., ... Ryan, N. D. (2016). A randomized clinical trial comparing individual cognitive behavioral therapy and child-centered therapy for child anxiety disorders. Journal of Clinical Child and Adolescent Psychology, 1-13. Retrieved from https://doi.org/10.1080/15374416.2016.1138408

Simons, C. J., Hartmann, J. A., Kramer, I., Menne-Lothmann, C., Hohn, P., van Bemmel, A. L., ... Wichers, M. (2015). Effects of momentary self-monitoring on empowerment in a randomized controlled trial in patients with depression. European Psychiatry, 30(8), 900-906. Retrieved from https://doi.org/10.1016/j.eurpsy.2015.09.004

Steptoe, A., \& Wardle, J. (2011). Positive affect measured using ecological momentary assessment and survival in older men and women. Proceedings of the National Academy of Sciences of the United States of America, 108(45), 18244-18248. Retrieved from https://doi.org/ 10.1073/pnas.1110892108

Sterling, P. (2014). Homeostasis vs. allostasis: Implications for brain function and mental disorders. JAMA Psychiatry, 71(10), 1192-1193. Retrieved from https://doi.org/10.1001/jamapsychiatry.2014.1043

Strauss, J., Peguero, A. M., \& Hirst, G. (2013). Machine learning methods for clinical forms analysis in mental health. Studies in Health Technology and Informatics, 192, 630-639.

Tugade, M. M., Fredrickson, B. L., \& Barrett, L. F. (2004). Psychological resilience and positive emotional granularity: Examining the benefits of positive emotions on coping and health. Journal of Personality, 72(6), 1161-1190. Retrieved from https://doi.org/10.1111/ j.1467-6494.2004.00294.x

van Knippenberg, R. J., de Vugt, M. E., Ponds, R. W., Myin-Germeys, I., van Twillert, B., \& Verhey, F. R. (2016). Dealing with daily challenges in dementia (deal-id study): An experience sampling study to assess caregiver functioning in the flow of daily life. [Epub ahead of print] International Journal of Geriatric Psychiatry. Retrieved from https://doi.org/10.1002/gps.4552

van Os, J., Delespaul, P., Barge, D., \& Bakker, R. P. (2014). Testing an mHealth momentary assessment routine outcome monitoring application: A focus on restoration of daily life positive mood states. PLoS One, 9(12), e115254. Retrieved from https://doi.org/10.1371/ journal.pone.0115254

Verhagen, S. J., Hasmi, L., Drukker, M., van Os, J., \& Delespaul, P. A. (2016). Use of the experience sampling method in the context of clinical trials. Evidence-Based Mental Health, 19(3), 86-89. Retrieved from https://doi.org/10.1136/ebmental-2016-102418

Vrijens, D., Drossaerts, J., van Koeveringe, G., Van Kerrebroeck, P., van Os, J., \& Leue, C. (2015). Affective symptoms and the overactive bladder-A systematic review. Journal of Psychosomatic Research, 78(2), 95-108. Retrieved from https://doi.org/10.1016/j.jpsychores.2014. 11.019 
Walz, L. C., Nauta, M. H., \& aan het Rot, M. (2014). Experience sampling and ecological momentary assessment for studying the daily lives of patients with anxiety disorders: A systematic review. Journal of Anxiety Disorders, 28(8), 925-937. Retrieved from https:// doi.org/10.1016/j.janxdis.2014.09.022

Wichers, M., Barge-Schaapveld, D. Q., Nicolson, N. A., Peeters, F., de Vries, M., Mengelers, R., \& van Os, J. (2009). Reduced stresssensitivity or increased reward experience: The psychological mechanism of response to antidepressant medication. Neuropsychopharmacology, 34(4), 923-931. Retrieved from https://doi.org/10.1038/ npp.2008.66

Wichers, M., Groot, P. C., \& ESM-Merge Group. (2016). Critical slowing down as a personalized early warning signal for depression. Psychother apy and Psychosomatics, 85(2), 114-116. Retrieved from https://doi.org/ 10.1159/000441458

Wichers, M., Myin-Germeys, I., Jacobs, N., Peeters, F., Kenis, G., Derom, C., ... Van Os, J. (2007). Genetic risk of depression and stress-induced negative affect in daily life. British Journal of Psychiatry, 191, 218223.

Wichers, M., Peeters, F., Rutten, B. P., Jacobs, N., Derom, C., Thiery, E., ... van Os, J. (2012). A time-lagged momentary assessment study on daily life physical activity and affect. Health Psychology, 31(2), 135-144. Retrieved from https://doi.org/10.1037/a0025688

Wichers, M., Schrijvers, D., Geschwind, N., Jacobs, N., Myin-Germeys, I., Thiery, E., ... van Os, J. (2009). Mechanisms of gene-environment interactions in depression: Evidence that genes potentiate multiple sources of adversity. Psychological Medicine, 39(7), 1077-1086. Retrieved from https://doi.org/10.1017/S0033291708004388

Wichers, M., Simons, C. J., Kramer, I. M., Hartmann, J. A., Lothmann, C., Myin-Germeys, I., ... van Os, J. (2011). Momentary assessment technology as a tool to help patients with depression help themselves. Acta Psychiatrica Scandinavica, 124(4), 262-272. Retrieved from https://doi.org/10.1111/j.1600-0447.2011.01749.x

Wichers, M. C., Myin-Germeys, I., Jacobs, N., Peeters, F., Kenis, G., Derom, C., ... van Os, J. (2007). Evidence that moment-to-moment variation in positive emotions buffer genetic risk for depression: A momentary assessment twin study. Acta Psychiatrica Scandinavica, 115(6), 451-457. Retrieved from https://doi.org/10.1111/ j.1600-0447.2006.00924.x

Wigman, J. T., Collip, D., Wichers, M., Delespaul, P., Derom, C., Thiery, E., ... van Os, J. (2013). Altered transfer of momentary mental states (ATOMS) as the basic unit of psychosis liability in interaction with environment and emotions. PLoS One, 8(2), e54653. Retrieved from https://doi.org/10.1371/journal.pone.0054653

How to cite this article: van Os J, Verhagen S, Marsman A, et al. The experience sampling method as an mHealth tool to support self-monitoring, self-insight, and personalized health care in clinical practice. Depress Anxiety. 2017;34:481-493. https://doi.org/10.1002/da.22647 